\title{
Joint Research Project env08 "Traceable measurements for monitoring critical pollutants under the European Water Framework Directive (WFD) 2000/60/EC"
}

\author{
Julie Cabillic ${ }^{\mathrm{a}}$, Sebastian Hein ${ }^{\mathrm{b}}$, Petra Lehnik-Habrink ${ }^{\mathrm{b}}$, Elisa Calabretta ${ }^{\mathrm{c}}$, Monica Potalivo ${ }^{\mathrm{c}}$, Maria Belli , Mine Bilsel $^{\mathrm{d}}$, \\ Taner Gokçen ${ }^{\mathrm{d}}$, Ahmet Ceyhan Goren ${ }^{\mathrm{d}}$, Ileana Crina ${ }^{\mathrm{e}}$, Mirella Buzuianu ${ }^{\mathrm{e}}$, Beatrice Lalere ${ }^{\mathrm{a}}$ and Rosemarie Philipp ${ }^{\mathrm{b}}$. \\ a. Laboratoire National de Métrologie et d'Essais (LNE), 1 rue Gaston Boissier, 75724 Paris cedex 15 France \\ b. Bundesanstalt für Materialforschung und -prüfung (BAM), Richard-Willstaetter-Str. 11, 12489 Berlin, Germany \\ c. Istituto Superiore per la Protezione e la Ricerca Ambientale (ISPRA), Via Enrico Fermi 2749, 21027 Ispra (VA) Italy \\ d. TUBITAK Ulusal Metroloji Enstitusu (TUBITAK), PK54 41470 Gebze Kocaeli Turkey \\ e. Biroul Roman de Metrologie Legala (BRML), Sos. Vitan Barzesti 11 Sector 4,042122, Bucuresti, \\ Romania
}

\begin{abstract}
The Joint Research Project ENV08 "Traceable measurements for monitoring critical pollutants under the European Water Framework Directive (WFD) 2000/60/EC" is a multi-partner trans-national project within the targeted call "Environment" of the European Metrology Research Programme (EMRP). The EMRP represents a metrology-focused European programme of coordinated research and development that facilitates closer integration of national research programmes. ENV08 deals with the grand challenges for multidisciplinary metrology in environment meeting "the most urgent industrial and societal needs" as stated in the EMRP Outline 2008. The project aims to provide reference methods capable of analysing priority hazardous substances specified in the WFD at the proposed low environmental quality standard concentrations in the body of ground, surface and coastal waters. In addition, ENV08 will answer the need for accuracy and comparability of measurements for the end users capabilities assessment by developing concepts for reference materials. ENV08 is coordinated by BAM (Germany) and involves 14 European institutes. Five institutes work on the development of a validated measurement procedure for Polycyclic Aromatic Hydrocarbons (PAH) in whole water samples at a concentration level required by the EU Water Framework Directive (WFD).
\end{abstract}

\section{Background}

The control of water pollution is an important issue with a large impact on human health and the environment. The European Water Framework Directive (WFD), Directive 200/60/EC [1], establishes a legal framework to protect and restore clean water across Europe. It specifies a list of 33 priority water pollutants which present a significant risk to or via the aquatic environment. According to the WFD, "good chemical status" for a water body is obtained when the priority substances concentrations in water, sediments or biota are below the Environmental Quality Standards (EQS). For reliable contaminants measurements at the EQS level, the Directive 2009/90/EC (QA/QC Directive) [2] requires analytical methods for laboratory tests which can reach a limit of quantification (LOQ) equal to or lower than $30 \%$ of EQS with measurement uncertainty less than $50 \%$ at EQS. Such methods do not exist for all the priority pollutants [3]. Some European harmonized methods are already available through CEN/TC230 "Water analysis" and ISO/TC147 "Water quality" for a large number of substances but all are not compatible with the WFD in terms of the LOQ and applicability to whole water sample.

The WFD implementation strongly depends on the availability of primary analytical methods and materials for the priority substances specified in the Directive. Both are essential to provide traceability of the test laboratories results and to assure EU-wide comparable measurement results for waters assessments as required in the WFD. It also requires the water quality monitoring to be performed by methods that are in line with the CEN/ISO standards or with other national or international standards. This will ensure data provision of equivalent scientific quality and comparability.

The Joint Research Project ENV08 "Traceable measurements for monitoring critical pollutants under the European Water Framework Directive (WFD) 
2000/60/EC" is a pluridisciplinary project coordinated by BAM (Germany) involving 14 institutes (National Metrology Institutes, Designated Institutes, Joint Research Center and excellence research institutes) from 10 European countries and the European Commission. The research work will provide the metrological basis for the WFD implementation by developing primary reference methods and concepts for the production of reference materials for selected priority hazardous substances analysis: TBT, PBDE and PAH. This presentation will focus on the development of measurement methods for PAH in whole water sample.

\section{Motivation and objectives}

Polycyclic Aromatic Hydrocarbons (PAHs) are ubiquitous environmental contaminants, naturally occurring in coal, crude oil and gasoline and their by products, e.g. coal tar or creosote. They are also generated by all incomplete combustion processes of organic materials: the major part is due to natural combustion such as forest fires and volcanic eruptions and the other part comes from entropic uses such as automobile exhausts, large-scale fires as for example wood stack fires and shelf fires. PAHs are persistent and have high carcinogenicity and mutagenicity effects, especially after being concentrated by biological chain [4]. Indeed they could induce oxidative stress and oxidative DNA damage through metabolic activation and generation of reactive oxygen species [5]. Therefore, PAHs are part of the 33 priority water pollutants of the WFD.

The aim of the work package dedicated to PAHs is a metrologically validated measurement procedure for the eight compounds defined in the priority substances list (Annex I of the 2008/105/CE Directive) as defined in the table 1.

Table 1: List of PAH studied and their associated EQS and LOQ

\begin{tabular}{|c|c|c|c|}
\hline \multicolumn{2}{|c|}{ Compounds } & $\begin{array}{c}\text { EQS } \\
\left(\mu \mathrm{g} . \mathrm{L}^{-1}\right)\end{array}$ & $\begin{array}{c}\text { Target LOQ of the } \\
\mathrm{JRP}\left(\boldsymbol{\mu g} \cdot \mathrm{L}^{-1}\right)\end{array}$ \\
\hline Anthracène & Ant & 0.01 & 0.03 \\
\hline Fluoranthène & Fluo & 0.01 & 0.03 \\
\hline Naphtalène & Naph & 2.4 & 0.72 \\
\hline Benzo(a)pyrène & BaP & 0.05 & 0.015 \\
\hline Benzo(b)fluoranthène & BbF & 0.03 & 0.009 \\
\hline Benzo(k)fluorathène & BkF & 0.0006 \\
\hline Benzo(g,h,i)perylène & BghiP & \multirow{2}{*}{0.002} & 0.0006 \\
\hline Indeno(1,2,3-cd)pyrène & IndenoP & & \\
\cline { 1 - 2 }
\end{tabular}

As required by the Directive 2009/90/EC (QA/QC Directive), the LOQ should be equal or below a value of $30 \%$ of the relevant EQS with a measurement uncertainty less than $50 \%(\mathrm{k}=2)$. The main objective of this work is to develop the most promising measurement methods of PAHs in whole water in line with the requirements of the $\mathrm{QA} / \mathrm{QC}$ Directive. There are two principal challenges. The first one is to achieve the required LOQ especially for the $\mathrm{BbF}, \mathrm{BkF}, \mathrm{BghiP}$ and IndenoP for which the level of concentration is very low regarding the existing methods. The second one is to define how to analyse PAHs from whole water: one analysis of the whole sample or two separate analysis, one for suspended particulate matter (SPM) and the other for the filtered sample? The work is divided in three parts:

1. Development of measurement methods for PAHs in the dissolved part

2. Development of measurement methods for PAHs in the SPM

3. Development of measurement methods for PAHs in whole water sample

Experiments were carried out within the collaboration of five National Metrology Institutes: BAM (Germany), TUBITAK (Turkey), ISPRA (Italy), BRML (Romania) and LNE (France).

\section{Motivation and objectives}

The aim of this part is to develop different methods for the analysis of PAHs in water sample (without SPM) and identify the most promising one compatible with the QA/QC Directive. To provide realistic sample materials, sample waters were tested with and without spiking with purified humic acid (HA) [6] to mimic natural colloids.

According to the literature and to the existing International standard methods, the two most common extraction methods implemented for PAHs in aqueous sample are Liquid-Liquid Extraction (LLE) and Solid Phase Extraction (SPE). This two methods have been optimized associated with an analyse by isotopic dilution gas chromatography coupled with mass spectrometer (IDGC/MS) or by isotopic dilution liquid chromatography coupled to tandem mass spectrometry with an atmospheric pressure photoionization (ID-LC-APPI$\left.\mathrm{MS}^{2}\right)$.

\subsection{Optimisation of the chromatographic separation}

One important validation parameter is the selectivity, as some PAHs present the same detection ion. For each analytical methods, this was optimized in order to achieve the best separation of critical PAHs pairs.

\subsubsection{GC-MS}

Seven commercially available GC columns were evaluated with respect to their ability to separate critical pairs of PAHs. The performance of all columns tested is summarized in Table 2. Best separation of critical PAHs pairs could be achieved with DB-EUPAH and DB-17MS. 
Table 2: Separation efficiency

\begin{tabular}{|c|c|c|c|c|c|c|c|}
\hline & $\begin{array}{c}\text { DB- } \\
\text { EUPAH }\end{array}$ & $\begin{array}{c}\text { DB- } \\
\text { 17MS }\end{array}$ & $\begin{array}{c}\text { BPX- } \\
\mathbf{3 5}\end{array}$ & $\begin{array}{c}\text { ICB- } \\
\text { PAH }\end{array}$ & $\begin{array}{c}\text { DB- } \\
\text { 5MS }\end{array}$ & HT-8 & XLB \\
\hline $\mathbf{1}$ & +++ & +++ & +++ & +++ & +++ & +++ & +++ \\
\hline $\mathbf{2}$ & +++ & +++ & ++ & + & + & - & - \\
\hline $\mathbf{3}$ & +++ & +++ & +++ & +++ & +++ & +++ & +++ \\
\hline $\mathbf{4}$ & +++ & +++ & +++ & +++ & +++ & +++ & ++ \\
\hline
\end{tabular}

$\mathbf{1}=$ Phenanthrene/Ant;

$\mathbf{2}=\mathbf{B b F} / \mathbf{B k F} /$ Benzo(j)fluoranthene

3 $=\mathbf{B a P} /$ Benzo(e)pyrene;

4=IndenoP/Dibenzo(a,h)anthracene/ Dibenzo(a,c)anthracene

$+++=$ very good separation, ++ good separation, + acceptable separation, - unsatisfying separation

\subsubsection{LC-APPI-MS ${ }^{2}$}

Four commercially available LC columns were evaluated with respect to their ability to separate critical pairs of PAHs:

- ACQUITY UPLC BEH Shield RP18 2.1x100 mm 1.7 micron

- ACQUITY UPLC BEH C18 2.1x100 mm 1.7 micron

- Phenomenex Envirosep PP 2.00x125 mm 5 micron

- Zorbax Eclipse PAH 2.1x50 mm 1.8 micron 600 Bar.

Best results were obtained with Zorbax Eclipse $\mathrm{PAH}$ column.

\subsection{Liquid liquid extraction}

On one hand, two types of waters were tested: demineralised water and drinking water. They were spiked with the 8 PAHs at a concentration level of 15 ng/L. Deuterated PAH analogues were used as internal standards and benzo(e)pyrene-D12 was used as an injection standard. Regarding the bibliography and the existing standards, cyclohexane was chosen as solvent and two extraction cycles of $25 \mathrm{~mL}$ were selected. Three extraction methods were compared with respect to the recovery of PAHs:

- shaking / shaking:

30 min shaking with $25 \mathrm{ml}$ cyclohexane at $300 \mathrm{~min}-1$

30 min shaking with $25 \mathrm{ml}$ cyclohexane at $300 \mathrm{~min}-1$

- stirring / shaking 1:

30 min stirring with $25 \mathrm{ml}$ cyclohexane at $48 \%$

30 min shaking with $25 \mathrm{ml}$ cyclohexane at $300 \mathrm{~min}-1$

- stirring / shaking 2:

30 min stirring with $25 \mathrm{ml}$ cyclohexane at $48 \%$

phase separation via micro separator

30 min shaking with $25 \mathrm{ml}$ cyclohexane at $300 \mathrm{~min}-1$.

Six determinations were performed for each extraction method and each type of water sample. All three methods yielded comparable results. Good recovery rates between $90 \%$ and $110 \%$ were observed for all target analytes in demineralised and drinking water. Variation coefficients were in the range between $2 \%$ and $10 \%$. For further investigations the shaking method was used because it is less laborious to implement than stirring/shaking.

On the second hand, water samples with HA were prepared. Target analytes and internal standards were spiked as described above. Since equilibration of the internal standard is the critical step in the presence of HA, extractions were performed at various times after adding the analyte / internal standard to the solution. Results show that the internal standard must be allowed to equilibrate at least $24 \mathrm{~h}$ with the HA to achieve good recoveries.

The analytical method achieves the LOQ required by the WFD using the Large Volume Injection of $20 \mu \mathrm{l}$.

\subsection{Solid phase extraction}

Several cartridges were tested with different phases (C18, polymeric or combination of two phases), different volume of phases (200 $\mathrm{mg}$ to $1.5 \mathrm{~g}$ ) from different suppliers. One litter of sample spiked with humic acids and PAHs (at EQS concentration levels) was extracted and analysed by GC/MS.

Results showed that for all the cartridges absolute recoveries were between 15 and $70 \%$ for the 6-7 rings PAHs (BbF, BkF, BaP, BghiP and IndenoP). Best recoveries $(50-70 \%)$ were obtain for three cartridges: Strata X (200mg, Phenomenex), Chromabond NH2-C18 (1g-500mg, Macherey-Nagel) and Chromabond C18 PAH (2g, Macherey Nagel).

Further investigations are in process in order to improve the efficiency of the extraction.

In parallel, extraction with speedisks is in progress in order to compare its efficiency with that of cartridges for the dissolved phase of the whole water sample. Two types of phases (C18 and polymeric) are tested using a SPE DEX 4790 extraction system.

\section{Development of measurement methods for PAH in the particulate matter}

Whole water, as defined in the WFD, includes the dissolved and particulate fractions. PAHs (especially five- and six- rings) are compounds that strongly adsorb to particles. Special attention is then required to ensure complete extraction of bound compounds. In water bodies containing high levels of SPM, separate analysis of SPM and of the filtered sample is usually the best option.

Standardised methods for PAHs in sediments and soils already exist, but they are only available for sample amounts larger than $1 \mathrm{~g}$. To collect a large amount of SPM, it is necessary to filter a large volume of water (1100 litres), which can be difficult to implement. The challenge is to develop a method able to extract a low amount of sample (i.e. up to $500 \mathrm{mg}$ of SPM). The most 
common methods for extraction of PAHs from solids are Soxhlet, sonification, pressurised liquid extraction (PLE) and microwave assisted extraction (MAE). In this project, PLE and MAE are assessed.

First tests have been done with the Certified Reference Material (CRM) LGC6188 (PAH in river sediment). For the MAE extraction there is no significant influence of the sample intake between 50 to $500 \mathrm{mg}$. PLE experiments are under process. The second step, which is under way, consists of filtrating a water spiked with the LGC6188 and analysed the filtrate. The optimisation of the method is under way.

\section{Development of measurement methods for PAHs in whole water}

European and International standards have been reviewed by Lepom et al. [3] in order to answer the following specific question, among others: "Are the existing standard methods applicable to the analysis of wholewater samples as required by the WFD?'. Lepom et al. [3] concluded that there were no consistent procedures on how to deal with samples containing substantial amounts of SPM (up to $500 \mathrm{mg} / \mathrm{L}$ ), implying that most methods have not been validated for such kinds of water sample.

This part of the study will be done using methods developed in the previous tasks. The aim is to compare two different approaches:

- extraction and analysis of whole water sample without phase separation

- $\quad$ filtration and separate analysis of both fractions. This work will begin when the previous tasks will be completed.

Acknowledgement: The research leading to these results has received funding from the European Union on the basis of Decision No 912/2009/EC.

\section{References}

[1] Directive 2000/60/EC of the European Parliament and of the Council of 23 October 2000 establishing a framework for Community action in the field of water policy.

[2] Directive 2009/90/EC of the European Parliament and of the Council of 31 July 2009 establishing technical specifications for chemical analysis and monitoring of water status.

[3] P. Lepom, B. Brown, G. Hanke, R. Loos, P. Quevauvillier and J. Wollgast, J. Chromatogr A, 1216 , (2009)

[4] L.Z. Zhu, X.F. Cai, J. Wang, J. Environ. Sci. 17 (2005)

[5] A. Valavanidis, T. Vlachogianni, S. Triantafillaki, M. Dassenakis, F. Androutsos, M. Scoullos, Estuar. Coast. Shelf Sci. 79 (2008)
[6] J. Van de Kreeke, B. De la Calle, A. Held, O. Bercaru, M. Ricci, P. Shegunova and P. Taylor, TrACs, 29 (2010) 